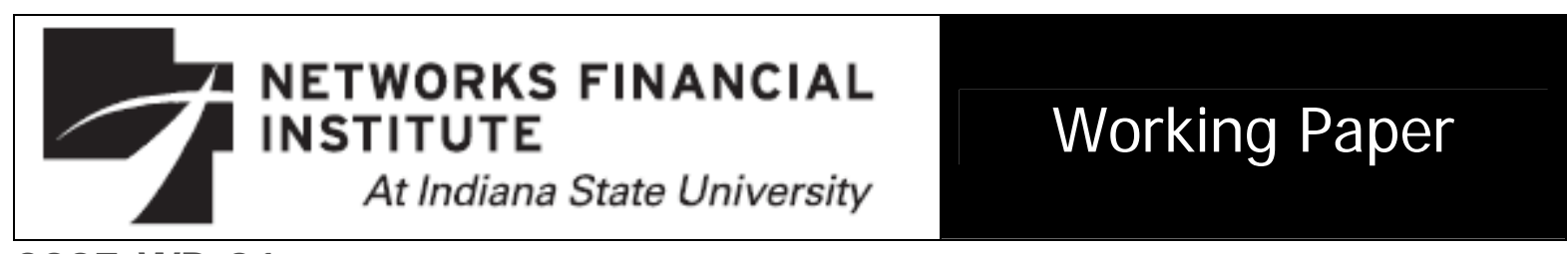

2007-WP-01

J anuary 2007

\title{
What's in a Score? \\ Differences in Consumers' Credit Knowledge Using OLS and Quantile Regressions
}

\section{Angela Lyons, Mitchell Rachlis and Erik Scherpf}

\begin{abstract}
Credit literacy depends, in part, on understanding credit report information and scores. The US Government Accountability Office (GAO) conducted a study in 2004 to assess consumers' knowledge of their credit report and credit score, and the dispute resolution process. This study uses the GAO data and estimates a series of OLS and quantile regressions to identify specific subgroups of the population that could benefit from more targeted consumer policies and financial education. The findings from this research have important implications for consumer educators, financial professionals, and policymakers, especially with respect to national strategies designed to improve consumers' financial well-being.
\end{abstract}

\section{About the Authors:}

Angela Lyons is an Assistant Professor at University of Illinois at Urbana-Champaign.

Mitchell Rachlis is an Adjunct Professor at George Mason University.

Erik Scherpf is research associate at the University of Illinois at Urbana-Champaign.

\section{Keywords:}

The views expressed are those of the individual author and do not necessarily reflect official positions of Networks Financial Institute. Please address questions regarding content to Angela Lyons at anglyons@illinois.edu. Any errors or omissions are the responsibility of the author.

NFI working papers and other publications are available on NFI's website (www.networksfinancialinstitute.org). Click "Research" and then "Publications/Papers." 


\section{What's in a Score? \\ Differences in Consumers' Credit Knowledge Using OLS and Quantile Regressions}

\section{Angela Lyons*, Mitchell Rachlis and Erik Scherpf}

Credit reports detailing personal credit histories and the credit scores derived from these reports affect many aspects of consumers' lives. Both credit reports and credit scores can influence lenders' decisions to grant credit and may affect individuals' ability to obtain jobs, insurance, and rental housing. Higher credit scores can improve the likelihood a loan will be granted and lower the interest rates offered on automobile, mortgage, and other consumer loans. Because of the importance of credit reports and credit scores, consumers need to know and understand what their reports contain. Many credit experts suggest that it is a prudent practice for consumers to check the accuracy and completeness of their credit report information periodically. However, it is not clear how well consumers understand what is in a credit report, what factors affect credit scores, and how to dispute information in a credit report.

Understanding consumers' level of credit literacy is vital to improving consumers' ability to manage their own credit.

The Fair and Accurate Credit Transactions Act (FACT Act) was enacted in 2003 and amended the Fair Credit Reporting Act (FCRA), a federal law that regulated, in part, who was permitted to access consumers' credit report information and how that information could be used. The FACT Act, among other things, extended provisions governing the credit reporting

\footnotetext{
${ }^{*}$ This article extends work previously conducted by the U.S. Government Accountability Office (\#GAO-05-223, Credit Reporting Literacy: Consumers Understood the Basics but Could Benefit from Targeted Educational Efforts). All views expressed in this paper are those of the authors and do not reflect the views or policies of the U.S. Government Accountability Office (GAO) or the views of other GAO staff members. The authors wish to thank James McDermott, Assistant Director of GAO Financial Markets and Community Investment, for his valuable comments and support of this research.
} 
system and addressed ongoing concerns about inaccuracies in credit reports by providing consumers with new tools to enhance the accuracy, security, and reliability of their financial information. For example, the act expanded access to credit information by entitling consumers to one free credit report each year. The FACT Act also included a provision mandating that the US Government Accountability Office (US GAO) examine consumers' knowledge and experience with credit reporting and identify the factors associated with consumers' understanding of credit reporting issues.

As part of its response to the mandate, the GAO conducted a study in 2004 to assess consumers' knowledge of credit reports, credit scores, and the procedures needed to correct credit reporting errors (US Government Accountability Office 2005). This study extends the work of the GAO. Specifically, the GAO data was used to estimate OLS and quantile regressions to determine how the impact of demographic factors varied across consumers with different levels of credit reporting knowledge. Results from the standard OLS model identified, in general, demographic groups that were less credit knowledgeable than others. The findings from the quantile regressions allowed for more precise identification of specific demographic subgroups that would likely benefit from more targeted financial education.

Current financial education research has moved away from using knowledge-based indicators and more towards looking at measures of behavior change (Lyons 2005; Lyons, Chang, and Scherpf 2006; Lyons, Palmer, Jayaratne, and Scherpf 2006). In addition, much of the existing research uses data collected from convenience samples such as participants of specific financial education programs (Lyons 2005; Lyons, Chang, and Scherpf 2006; Lyons, Palmer, Jayaratne, and Scherpf 2006). This study contributes to the literature by showing how valuable insight can be gained from a knowledge-based survey using a random sample of the 
U.S. population. This study also shows how quantile regression analysis, previously unused in financial education studies, can be a useful tool in identifying specific subgroups of consumers who could benefit from more targeted consumer policies and financial education.

\section{LITERATURE REVIEW}

A growing body of literature provides general insight into consumers' financial literacy levels and the factors that affect their financial knowledge and behavior. For an overview, see Bell and Lerman (2005), Braunstein and Welch (2002), Fox, Bartholomae, and Lee (2005), Hilgert, Hogarth, and Beverly (2003), Hogarth (2002), Hogarth, Beverly, and Hilgert (2003), Lyons (2005), Lyons, Palmer, Jayaratne, and Scherpf (2006), and National Endowment for Financial Education (2004). This research typically has concluded that providing financial information and education results in positive improvements in consumers' financial literacy levels.

Given the growing importance that credit reports and credit scores play in the lives of consumers, it has become particularly important that researchers study credit literacy so as to better understand how consumer education policy can be used to help improve consumers' ability to manage their own credit and ultimately their long-term financial security. Yet, little research has been conducted in this area.

In 2004, the U.S. GAO conducted a literature search to identify leading research related to consumers' knowledge of credit reporting issues and the extent to which consumers reviewed their credit reports and credit scores (U.S. GAO 2005). An attempt was made to evaluate the quality of this research, the data used, and the importance of the findings. However, limited documentation on survey design, methodology and sampling techniques made it difficult to conduct a thorough review (see U.S. GAO (2005), Appendix III). According to the GAO report, 
few studies attempted to investigate consumers' knowledge of credit reporting issues. Of those studies existed, most were primarily descriptive in nature and few used data collected from random samples of known populations.

The GAO cited a few studies for which there was some indication that a random sample of a known population had been used. The following are highlights from these studies that can serve as background information and later comparisons for the findings presented in this paper. For example, research conducted by AARP (2003), Consumer Federation of America (2003), Hilgert, Hogarth, and Beverly (2003), and Consumer Federation of America and Providian Financial (2004) investigated consumers' general knowledge about credit reports and scores including: how information is collected; how credit reports and scores can be obtained; the factors that impact credit histories; and consumers experiences in reviewing their own credit reports and scores. The findings from these studies tended to show that many Americans lack basic knowledge about credit reports and scores. One study by Consumer Federation of America and Providian Financial (2004), which focused primarily on consumers' knowledge about credit scores, found that most consumers do not understand their scores, even when they think their knowledge of credit is good. Specifically, those who thought their knowledge of credit scores was "good" frequently answered credit knowledge questions incorrectly. Not surprisingly, it also was reported that those who considered their knowledge of credit scores to be "poor" were more likely to know less about credit scores.

Additional research has investigated the credit reporting process including the accuracy of credit reports and the dispute process used to correct errors (i.e., Avery, Calem, Canner, and Bostic (2003) and Avery, Calem, and Canner (2004)). However, these studies do not adequately 
capture the extent to which consumers understand the dispute resolution process and their consumer rights with respect to credit reporting.

So what have we learned? Previous research provides basic insight into consumers' knowledge of credit reports and scores and the credit reporting process, but these are primarily descriptive in nature and are limited by the design, methodologies and sampling techniques. Few have used random samples of a known population. Also, few have used rigorous empirical methods to gain a more thorough understanding of consumers' credit literacy. In fact, to our knowledge, there are no financial literacy studies that have used quantile regression analysis, which allows us to conduct more targeted analysis and elucidate those factors that have a notable effect on particular segments of the population.

Koenker and Basset (1978) were the first to introduce quantile regression as an alternative to ordinary least squares (OLS). The primary advantages of the quantile approach are its robustness to violations of the assumption of a normal, or "Gaussian," distribution of errors, to outlier observations, and to monotonic transformations of the dependent variable. Moreover, quantile regression provides a more complete characterization of the impact of independent variables than OLS.

Researchers have applied quantile methods to an increasingly eclectic array of topics (for an overview, see Koenker and Hallock (2001)). However, we are not aware of any other studies that employ the quantile method to investigate credit or financial knowledge. The quantile studies that most closely relate to ours examine academic test scores.

For example, Eide and Showalter (1998) use quantile regression to examine the relationship between school quality and student performance. The dependent variable in their model is the change in the score on a standardized mathematics test between the student's 
sophomore and senior year. They measure the effect of the key independent variables on changes in test scores at the $5^{\text {th }}, 25^{\text {th }}, 50^{\text {th }}$, and $95^{\text {th }}$ percentiles, in addition to measuring the mean effect of these variables using OLS. The OLS regression yields insignificant results for the key policy variables, such as pupil-teacher ratio, length of the school year, district level per pupil expenditures and educational attainment of the instructors. The quantile regressions, however, reveal positive effects for some measures of school performance. For instance, Eide and Showalter found that lengthening the school year had positive and significant effects on students with test score gains at the $50^{\text {th }}, 75^{\text {th }}$, and $95^{\text {th }}$ percentiles. Also, per pupil district-level expenditures had a significantly positive effect on test scores gains for students at the $5^{\text {th }}$ percentile. By supplementing the OLS analysis with quantile methods, Eide and Showalter provide important additional information to policymakers.

Similarly, Bassett, Tam and Knight (2002) employ quantile regression to estimate the cross-sectional relationship between the characteristics of a student's high school and his/her ACT score. In this study, the use of quantile regression revealed significant differential effects of key independent variables, such as pupil-teacher ratio and teacher qualification, on the test performance of high and low scorers - effects that previous research, relying solely on OLS methods, failed to detect.

Levin (2001) also employs quantile regression to take a fresh look at the impact of class size and peer effects on high school test scores. An examination of the raw achievement distribution in his data is not associated with a clear increase or decrease in class size, suggesting "no discernable difference in class size effect between different quantiles of the conditional achievement distribution." Levin finds evidence that class size is not exogenous with respect to student achievement, necessitating the use of a two-stage quantile method (2SLAD). Levin's 
study also incorporates peer effects and his results indicate that the effect of class size on student achievement works primarily through peer effects rather than through the direct effect of increased resources devoted to each student. In particular, a key finding is that the peer effects are strongest for students at the lower end of the achievement distribution.

Other researchers have used quantile regression to investigate the effect of education on the distribution of earnings (Bedard 1998; Buchinsky 1994, 1998). From a policy perspective, the usefulness of the quantile approach lies in its ability to uncover effects specific to particular subpopulations, which in turn permits researchers to formulate education and policy

recommendations better tailored to the needs of specific subgroups of the population. We apply this technique to investigate how the impact of various factors changes across the conditional distribution of consumers' credit knowledge scores. We compare the quantile findings with the OLS results.

\section{SURVEY DATA}

\section{Sampling Methods}

Between July and October 2004, data was collected from a random sample of U.S. consumers using a telephone survey that was administered by a private research firm under contract to the GAO. The firm used random-digit dialing methods to generate a probability sample of non-institutionalized U.S. adults 18 and over. To ensure that financial knowledge and behaviors within selected subgroups could accurately be assessed, phone numbers for certain subgroups were over-sampled. In particular, a relatively higher proportion of responses were included from (1) the seven states where consumers could receive at least one free credit report per year prior to the implementation of the FACT Act (Colorado, Georgia, Maine, Maryland, Massachusetts, New Jersey, and Vermont), (2) African-Americans, (3) Hispanics, (4) non- 
African Americans and non-Hispanics with annual family incomes under $\$ 25,000$. A minimum number of interviews were specified for each of these subgroups. The quotas were achieved in ways that distributed the over-sampled interviews naturally across the population. The selection of respondents within each household that was interviewed was also randomized.

In total, the firm obtained and dialed 9,784 randomly generated phone numbers. The overall response rate for the telephone survey was 48 percent, where the response rate was calculated as the total number of usable surveys (complete and partially complete responses) divided by the total eligible sample that was called. The cooperation rate, which measures success at completing interviews with contacted individuals who were determined to be eligible, was 59 percent. The cooperation rate was calculated as the number of complete interviews divided by the total number of complete and partial interviews, refusals, and callbacks that were arranged but not completed. The final sample consisted of 1,578 usable responses. Weights were created to adjust the sample so that the results could be generalized to the population of U.S. adults aged 18 or older. Further details on the survey design, sampling, and response rates can be found in the GAO report (U.S. Government Accountability Office 2005).

\section{Survey Design}

The survey was designed to assess consumers' knowledge of credit reports, credit scores, and the dispute resolution process. The survey was developed using relevant information from existing surveys and studies that had previously asked consumers questions about financial knowledge and credit reporting issues. Input was gathered from multiple agencies and organizations including, but not limited to: the Federal Reserve Board (FRB), the American Association of Retired Persons (AARP), the Consumer Federation of America (CFA), the Federal Trade Commission (FTC), Fannie Mae Foundation, Freddie Mac, Fair Isaac 
Corporation, Jump\$tart Coalition, Consumer Data Industry Association, and the credit reporting agencies (Equifax, Experian, and TransUnion). Based on these sources of information, a set of survey questions were drafted that covered different aspects of credit reporting knowledge such as where credit reports and scores come from, what they are used for, and what factors influence them. Questions were also constructed to capture consumers' personal experiences and perceptions of credit reports, credit scores, and the dispute process including their perceptions about the processes of obtaining a credit report and reporting errors on their credit report. For example, consumers were asked if they had obtained a credit report or score, if they had ever disputed information on their credit report, whom they would contact first in the case of a dispute, and whether they believed that their credit report was understandable.

Respondents were asked a total of 58 questions. Twenty-three survey questions (worth a total of 56 points) were created to test consumers' knowledge of credit reporting issues. An additional 22 questions were included to obtain consumers' opinions about these issues and to examine their experiences with the credit reporting process. Additional question were asked to collect general demographic information on ethnicity, age, gender, education, employment status, investments and loans, and income level.

\section{Credit Knowledge Score}

A credit knowledge score was calculated for each respondent using the 23 credit knowledge questions in the survey. Using these questions, a respondent could earn a total of 56 points; 37 points based on 14 credit report questions, 12 points based on four credit score questions, and 4 points based on four questions related to the dispute resolution process. In

addition, consumers could earn three additional points by answering one question about the FACT Act. 
Most of the survey questions were multiple-choice and had pre-coded answers. In addition, some of these questions had one part, while others had several parts. If a respondent gave a correct answer to a multiple-choice question or a sub-part of a question, they were awarded one point for that question or subpart, respectively. No points were given for incorrect answers, for refusing to answer questions, or for answers of "don't know." A few questions were open-ended requiring unassisted responses. These questions asked consumers to provide their own explanation of what credit reporting agencies do, what credit reports are, and what credit scores are. A respondent received no points if their response was clearly incorrect or they said they did not know. They received one point if their response was partially correct or if their response was correct but vague. Two points were awarded if their response was more detailed and fully correct. Two GAO researchers separately reviewed and scored each open-ended response. After all the responses were scored, a third GAO researcher reviewed the assigned scores and adjudicated any differences in the scores between the first two researchers.

Consumers' average credit knowledge score was calculated as the percentage of correct answers to the 23 credit knowledge questions. (See the appendix at the end of this paper for a listing of the 23 survey questions used to calculate consumers' credit knowledge score and the number of points each question was worth.) The mean score on the survey was 55 percent with scores ranging from 0 to 91 percent. Consumers with higher credit knowledge scores were assumed to be more knowledgeable. Figure 1 shows the distribution of scores. The dotted line represents the kernel density estimate while the solid line represents the normal density function. A comparison of the two reveals that the scores closely follow a normal distribution.

\section{METHODOLOGY}


We use two different methodologies to determine differences in credit knowledge across demographic groups and how the impact of demographic factors varies across the distribution of consumers with different levels of credit knowledge. First, we estimate a standard Ordinary Least Squares (OLS) regression model, which yields the mean effect of each independent variable on the conditional distribution of credit knowledge scores. We then extend the standard OLS model and estimate a quantile regression model. This model allows us to measure the effect of each independent variable at any given part of the conditional distribution of credit knowledge scores. To illustrate, we can express the $\theta^{\text {th }}$ quantile of the dependent variable, y, conditional on a vector of independent variables, $x$, as $Q(\theta \mid x)=\alpha(\theta)+x \beta(\theta)$, where $0<\theta<1$. If the effect of the independent variable is constant throughout the distribution (i.e., $\beta(\theta)=\beta$, for all $\theta$ ), the quantile model reduces to the standard conditional expectation model, $E(y \mid x)=\alpha+x \beta$. However, if the true effect of $x$ varies at different points in the conditional distribution of $y$, the quantile method will reflect this by allowing the coefficient estimate, $\beta(\theta)$, to depend on the quantile, $\theta$.

The quantile approach thus provides a more complete picture of the influence of each independent variable on credit knowledge. In particular, quantile regression identifies potentially disparate effects of an independent variable across the conditional distribution of credit knowledge - differences that can be obscured in traditional OLS analysis. For instance, an OLS coefficient of $\beta=0$ could signify that the independent variable has no effect on credit knowledge or, given that $E(y \mid x)=\int Q(\theta \mid x) d \theta$, it could result from the OLS method aggregating offsetting quantile effects. That is, an independent variable could have a significant and positive effect in the left tail of the conditional distribution and a significant and negative effect in the 
right tail. Yet, the average effect estimated by the OLS coefficient might not be significantly different from zero.

A key advantage of the quantile approach is that it can reveal effects of independent variables that are significant only in parts of the conditional distribution. Quantile regression is thus useful for identifying effects relevant for key sub-populations. In the context of this study, quantile regression can highlight characteristics associated with poor credit knowledge, which is useful for developing programs appropriate for financially at-risk groups. We are particularly interested in observing behavior in the tails of the credit knowledge distribution, where we are most likely to uncover effects not captured in traditional OLS analysis.

An estimate of the linear conditional expectation function, $E(Y \mid x)$, can be obtained by solving the following optimization problem:

$$
\min _{\beta} \sum(y-x \beta)^{2}
$$

As is well known, the estimate of the OLS coefficient $\beta$ is obtained by minimizing the sum of the squared residuals. Quantile estimates are obtained similarly by solving,

$$
\min _{\beta} \sum \rho_{\theta}(y-x \beta)
$$

where $\rho_{\theta}(u)=u(\theta-I(u<0))$ is a piecewise linear "check function" for any quantile between $0<\theta<1$. When $\theta=1 / 2, \rho_{\theta}$ reduces to the absolute value function and equation (2) becomes a conditional median function. Thus, for the special case of a median regression, the coefficients are derived by minimizing the sum of the absolute value of residuals. For any other quantile, the coefficients are derived by minimizing a 'tilted' or 'weighted' sum of the absolute-value function, where the weight function depends on the signs of the residuals and the quantile (i.e., position in the distribution). See Koenker and Hallock (2001) for more details. 
For the purposes of this study, let $y_{i}$ denote the $i^{\text {th }}$ respondent's credit knowledge score, and let $x_{i}$ denote a vector of personal characteristics of the respondent. The credit knowledge scores, $y_{i}$, are assumed to be independent with distribution function, $F\left(z \mid x_{i}\right)$. In the standard OLS model, credit knowledge is expressed as a linear function of personal characteristics:

$$
\mathrm{E}\left(\mathrm{y}_{\mathrm{i}} \mid \mathrm{x}_{\mathrm{i}}\right)=\alpha+\mathrm{x}_{\mathrm{i}} \beta .
$$

Hence, the OLS coefficient $\beta$ captures the impact of personal characteristics on average credit knowledge scores, conditional on $x_{i}$. In the linear quantile model, the effect of personal characteristics on credit knowledge, can vary with the quantile of credit knowledge scores, $\theta$. The relationship between credit knowledge and personal characteristics can thus be specified as: $Q\left(\theta \mid x_{i}\right)=\alpha(\theta)+x_{i} \beta(\theta)$.

There are many factors that might potentially affect a respondent's level of credit knowledge. The independent variables, $x_{i}$, that we were able to control for include ethnicity, age, annual household income, employment status, gender, education levels, had a mortgage or auto loan, requested a copy of credit report, pulled credit score, disputed contents of credit report, experienced identity theft, and lived in a free credit report state. Several of these variables reflect factors that could directly or indirectly affect consumers' knowledge of, and experience with, credit reporting. For example, respondents were asked if they lived in a state where they could receive free copies of their credit reports each year prior to the passage of the Fair and Accurate Credit Transactions Act (FACT Act). It was hypothesized that having this right might encourage more individuals to look at their credit reports, which could increase their credit reporting knowledge. Similarly, it was hypothesized that having a mortgage or an automobile loan could mean that consumers were more likely to know about credit reporting issues based on their ongoing experiences with borrowing. Other experience-related factors that might influence 
consumers' knowledge and understanding of credit reporting issues include having seen a credit report or credit score, disputing information on a credit report, and experiencing identity theft.

\section{DESCRIPTIVE STATISTICS}

\section{Responses to Credit Knowledge Questions}

Table 1 presents selected items from the credit knowledge survey along with the percentage of respondents answering each item correctly. Note that in this table and all remaining tables the statistics have been weighted to reflect the U.S. population. The first set of questions covers consumers' general knowledge about credit reporting. Eighty-two percent of respondents provided an accurate definition of a credit reporting agency (CRA), and 70.9 percent were aware of their right to obtain their credit report at any time. However, less than half of the respondents (46.8 percent) knew that information could remain on their credit report for up to seven to ten years, and less than ten percent ( 7.2 percent) were aware that lenders were not required to report loan information such as history of loan repayment to any of the CRAs.

In general, respondents had very good knowledge of the ways in which their credit history could impact their life. Nearly all respondents (94.9 percent) were aware that their credit history could affect their ability to get a loan. In addition, most knew that it could affect the interest rate on a loan ( 80.9 percent) and their ability to rent an apartment (72.3 percent). Over 70 percent also knew that their credit history could not affect their ability to receive Social Security benefits (70.6 percent) and obtain a driver's license (86.1 percent). However, the majority of respondents did not know that their credit history could affect insurance coverage and premiums (only 36.0 percent correct responses). They also did not know that it could affect their employment prospects (only 32.8 percent correct responses). 
With respect to the contents of a credit report, most respondents knew that their social security number (71.2 percent), credit history ( 81.8 percent), and bankruptcies ( 86.6 percent) were included on their credit report. However, substantially fewer respondents knew that race (59.4 percent) and checking account balances (57.9 percent) were not included on their report. Even fewer knew that income was not included (37.5 percent).

While more than two-thirds of respondents (68.4 percent) knew the definition of a credit score, only 28.2 percent could name a number within a possible credit score range. This suggests that while most respondents knew what a credit score was 'in theory,' their practical knowledge of credit scores was lacking. Knowledge of the factors that positively and negatively affect credit scores was also mixed. Most respondents knew that making late payments and skipping loan payments could negatively affect their credit score (87.0 and 86.9 percent, respectively). However, fewer were aware that frequently applying for credit (59.9 percent) and using most of their available credit (51.5 percent) could negatively affect their score. In addition, only 50.0 percent knew that requesting a copy of their own report had no effect on their score, and only 43.4 percent knew that having low checking account balances also had no effect.

Finally, the vast majority of respondents knew they had the right to dispute information on their credit report (89.8 percent), but most did not fully understand their rights in the dispute process. For example, only 40.6 percent knew that they could add a personal statement to their report if they were unable to resolve a disputed item, and only 28.1 percent were aware that credit reporting agencies (CRAs) investigated incorrect information on credit reports at no cost to the consumer. 


\section{Sample Demographics}

Table 2 presents a demographic profile of the sample. The first column reports summary statistics for the entire sample, and the remaining columns report them by quartile based on the distribution of credit knowledge scores, where higher quartiles consist of individuals with higher scores. With respect to general demographics, whites accounted for 68.8 percent of the sample, followed by Hispanics (13.9 percent), blacks (12.4 percent) and other groups (4.9 percent). Across the distribution, the proportion of whites increased with credit knowledge scores, while the proportion of Hispanics progressively decreased. Aside from a slight drop off at the $3^{\text {rd }}$ quartile, the proportion of blacks stayed roughly constant across the distribution of scores.

The average age of respondents was 45.2 years. However, the average age decreased slightly across the distribution of credit knowledge scores such that those with higher scores were more likely to be younger than those with lower scores. This may suggest that beyond a certain age, additional experience does not necessarily translate into greater credit reporting knowledge.

Income was, for the most part, evenly distributed in the sample. Households with total annual income below $\$ 25,000$ made up the largest income group (28.2 percent), while those with household income between $\$ 50,000$ and $\$ 74,999$ made up the smallest income group (20.3 percent). The proportion of households earning below $\$ 25,000$ decreased sharply across the distribution of scores, ranging from 58.7 percent at the $1^{\text {st }}$ quartile to 11.1 percent at the $4^{\text {th }}$ quartile. As expected, we observed the opposite pattern for the highest income category (\$75,000 and above). This income group accounted for only 7.8 percent of the sample at the lowest quartile and 42.2 percent at the highest quartile. Apart from a slight drop-off at the highest quartile, the proportion of households earning between $\$ 50,000$ and $\$ 74,999$ also was 
increasing across the distribution of credit knowledge scores. The proportion of households earning between $\$ 25,000$ and $\$ 49,999$ annually initially increased, peaked at the $2^{\text {nd }}$ quartile, and then decreased at the higher quartiles.

Over half of the respondents (60.4 percent) were employed, either full-time or part-time, and nearly one-third (31.1 percent) were unemployed. Students, and individuals reporting an alternative employment status, accounted for 3.7 and 4.8 percent of the sample, respectively. Not surprisingly, those with higher credit knowledge scores were more likely to be employed, while those with lower scores were more likely to be unemployed. The pattern was less discernable for the other employment categories. However, it may be interesting to note that the proportion of students was highest at the $2^{\text {nd }}$ quartile of credit knowledge and then fell off slightly at the $4^{\text {th }}$ quartile, indicating that students may lack the advanced knowledge that comes with greater financial experience.

With respect to gender, females comprised only a slightly larger proportion of the sample than males (51.6 percent vs. 48.4 percent). At the $1^{\text {st }}$ quartile of the credit knowledge distribution, however, we observe a much larger 'gender gap.' Females accounted for 60.4 percent of the sample at the $1^{\text {st }}$ quartile, while males made up only 39.5 percent of the quartile. At higher quartiles, the difference between the proportion of males and females was very small.

Education levels were almost equally represented in the sample, with the exception of the "less than high school" category, which accounted for only 10.4 percent of respondents. Once again, we observed the expected patterns across the quartiles. Those with higher credit knowledge scores were more likely to have a college degree and less likely to complete high school. The educational differences across the distribution of credit knowledge scores were particularly striking between those who had less than a high school education and those who 
received at least some post-secondary education, even if they did not complete a 4-year degree. For example, 32.8 percent of those who scored in the lowest quartile had less than a high school education compared to 7.1 percent in the $2^{\text {nd }}$ quartile and 3.9 and 4.1 percent in the $3^{\text {rd }}$ and $4^{\text {th }}$ quartiles, respectively. Only 10.8 percent of those in the lowest quartile had a college degree compared to 51.1 percent in the highest quartile.

With respect to financial experience, we found that more than three-fourths (77.7 percent) of the sample had a mortgage or auto loan. In addition, more than half (57.8 percent) had requested a copy of their credit report, and nearly one-third (32.8 percent) had pulled their credit score. However, only 17.9 percent had previously disputed the contents of their credit report, and 9.8 percent had experienced identity theft. Almost 13.0 percent lived in a free credit report state prior to the FACT Act.

\section{RESULTS}

\section{OLS Regression Results}

The first set of columns in Table 3 presents the weighted coefficients and standard errors for the OLS linear regression model. The results show that most of the independent variables were statistically significant. For example, having higher levels of income and education significantly increased a respondent's credit knowledge score. Moreover, the magnitude of the education effect increased with higher levels of education. There was little evidence, however, that the magnitude of the income effect increased with income level. Being older and unemployed significantly decreased credit knowledge scores. In addition, Hispanics had significantly lower scores compared to whites, while blacks did not. It is interesting to note that the largest positive marginal effects were found for education while the largest negative marginal effects were found for Hispanics. Specifically, those with a college education scored 13.8 
percentage points higher on average than those who did not complete high school. Hispanics scored 6.3 percentage points lower than whites holding all other things constant. The OLS coefficient for gender was positive but not significantly different from zero, suggesting that males did not possess more knowledge about credit reporting than females.

The findings from the OLS regression also showed how prior financial experiences can significantly influence credit knowledge. Having had a mortgage or an automobile loan, having requested a credit report or credit score, and having disputed an error on a credit report were each significantly different from zero at the 1.0 percent level. Specifically, having had a mortgage or an automobile loan increased a respondent's score by 3.7 percentage points on average. Similarly, having requested a credit report or credit score raised a respondent's score by 5.1 and 4.2 percentage points, respectively. Having disputed an error on a credit report increased a score by 5.1 percentage points. These increases were consistent with the hypothesis that increased experience with credit and credit reports improves consumers' knowledge of these issues.

Having lived in a free credit report state and having experienced identify theft were both insignificant at conventional levels. This result is rather intuitive though-requesting a credit report or credit score, disputing the contents of a credit report and obtaining a mortgage or auto loan each require the active involvement of the individual and thus are more likely to be 'learning experiences.' By contrast, living in free credit report state or experiencing identity theft would, in and of themselves, not necessarily increase an individual's financial knowledge.

\section{Quantile Regression Results}

The remaining columns in Table 3 present the regression results for the $10^{\text {th }}, 25^{\text {th }}, 50^{\text {th }}$, $75^{\text {th }}$, and $90^{\text {th }}$ quantiles. Recall that quantile regressions were estimated to determine if the impact of the independent variables varied for consumers at different points in the distribution of 
credit knowledge scores. Specifically, did the independent variables have a different impact on the credit knowledge scores of consumers who scored lower in the distribution versus those who scored higher? The results of the quantile regressions showed that the position of a respondent in the credit knowledge distribution did, in fact, significantly affect the impact that various independent variables had on their level of credit knowledge.

For example, the quantile analysis showed that the effect of each education category was positive and significantly different from zero throughout the conditional distribution of financial knowledge scores. However, it also revealed a significant and positive spike in the effect of each education category around the $20^{\text {th }}$ quantile. This suggests that education had a more positive impact on scores for those who were less financially knowledgeable about credit reporting. Hence, the quantile analysis broadly confirms that the OLS result of a strong, positive effect of education holds throughout the conditional distribution. However, it also reveals behavior in the lower part of the credit knowledge distribution not evident in the OLS analysis; namely, that higher levels of education had the greatest positive impact for individuals who were otherwise not very financially knowledgeable.

Recall that another striking result from the OLS regression was the strong, negative effect that being Hispanic had on an individual's credit knowledge score. The quantile analysis showed that this deficiency affected Hispanics across all levels of credit knowledge, but it also suggested that the credit knowledge deficiency was less severe in the right tail of the distribution, at higher knowledge levels.

The quantile regressions also point to a more nuanced effect for gender than was revealed by the statistically insignificant OLS estimate. At the $25^{\text {th }}$ quantile, the coefficient on male was roughly three times as large as the OLS estimate (1.786 vs. 0.586$)$ and was marginally significant 
at the 10.0 percent level. In the right tail of the distribution, at the $90^{\text {th }}$ quantile, the effect became negative and significant at the 5.0 percent level. One interpretation is that, among those who are less financially knowledgeable, males tend to be slightly more knowledgeable about credit reporting than females. Among those who are more financially knowledgeable, however, males fare a bit worse than females. It should be stressed that the magnitudes of these effects were rather small, ranging from just below -2 to just above +2 . Nevertheless this differential effect of gender across the distribution of credit knowledge scores may merit further attention.

With respect to prior financial experience, we found that, unlike OLS, the quantile results showed significant effects for living in a free credit report state at the $25^{\text {th }}, 75^{\text {th }}$ and $90^{\text {th }}$ quantiles. It may be the case that individuals were more likely to be aware that they lived in a free credit report state if they had previously requested a credit report and were more familiar with what their report contained. The quantile regressions confirmed that being the victim of identity theft did not have a significant effect on credit knowledge at any of the quantiles considered in our analysis. The quantile approach also confirmed the significance of the other measures of financial experience throughout the conditional distribution of credit knowledge.

Additional evidence revealed that the effects of age, income, and employment status were consistent with OLS estimates in sign, but varied across the distribution with respect to significance levels and the magnitude of the effects.

\section{A Graphical Depiction}

Figure 2 presents a graphical representation of the quantile regression results. For each of the covariates, we plotted the quantile regression estimates (the jagged straight line). These point estimates can be interpreted as the impact of a one-unit change of the covariate on an individual's credit knowledge score holding the other covariates constant. For each figure, the 
horizontal axis indicates the quantile while the vertical axis specifies the credit knowledge score. The dashed line in each figure shows the OLS estimate of the conditional mean effect. The two dotted lines represent conventional 90 percent confidence intervals for the least squares estimate. The shaded gray area is the 90 percent pointwise confidence band for the quantile regression estimate.

Consider the graph that depicts the effect that a college education has on an individual's credit knowledge score; the figure is labeled 'College Grad.' At any given quantile, we want to know how different the corresponding credit knowledge scores are for those with a college education compared to those with less than a high school education. According to the OLS estimate of the mean effect (the dashed line in Figure 2), individuals with a college education have a credit knowledge score that is 13.8 percentage points higher than those with less than a high school education. However, if we look at the quantile regression estimates (the jagged straight line), the disparity is much larger than 13.8 percentage points at the $10^{\text {th }}$ quantile and only somewhat smaller at the $75^{\text {th }}$ quantile. Specifically, we see in Figure 2 that the estimate spikes to 24.6 percentage points at the $10^{\text {th }}$ quantile, which goes well beyond the range of the 90 percent confidence interval for the least squares estimate. For the $75^{\text {th }}$ quantile, it drops to only 10.6 percentage points, which is just outside the confidence interval. This graphical illustration shows how the conventional least squares confidence interval does a poor job of representing the range of disparities at the lower tail of the distribution. This type of analyses can be used to interpret the graphs for the other covariates.

\section{DISCUSSION AND CONCLUSIONS}

Given that credit reports and credit scores impact many important aspects of consumers' lives, it is increasingly important that consumers understand what is in their reports, how reports 
and scores are used, and the potential impacts of both. The findings from this research showed that most consumers generally understand the basics of credit reporting such as what credit reports and scores are and how they can be obtained. They also know that they have the right to dispute errors. However, this study revealed that many still lack specific knowledge about what information is contained in credit reports, how to dispute errors, and the possible impact of their credit history on such factors as insurance premiums and employment. Many also are unaware of how some behaviors can negatively or positively affect their credit scores. These findings cast some doubt on whether most consumers have an adequate working knowledge of important credit reporting issues.

In general, educational efforts could potentially increase consumers' knowledge of credit reporting by focusing on those areas in which consumers' knowledge was weakest. At the most basic level, consumer educators and financial professionals can find ways to increase consumers' awareness of the importance of obtaining credit reports and scores, checking for accuracy, correcting errors, and understanding the effects that everyday financial decisions can have on credit scores. More specifically, consumers would benefit from educational programs and initiatives that improve their understanding about what information is included in a credit report and what information has the greatest negative and what information has the greatest positive effect on their credit score and thus their access to credit. Instruction on how to obtain credit reports and credit scores and how to review credit reports for accuracy and completeness would also be beneficial. In addition, consumers need a better understanding of their rights with respect to the dispute process.

From the standard OLS model, we were able to identify demographic groups that were significantly less knowledgeable about credit reporting than others. Specifically, the results 
showed that consumers who were less educated, lower-income, older, or Hispanic tended to be less knowledgeable. The findings also showed that those with higher credit knowledge scores were more likely to have prior experiences with credit, suggesting that consumers "learn by doing" and are more informed when they have gained financial experience.

Educators and financial professionals can address the gap in credit knowledge by helping to make consumers more aware of existing and credible resources such as consumer publications developed by the Federal Trade Commission and the Federal Reserve Board as well as the Financial Literacy and Education Commission's Web site and toll-free hotline. Since this study shows that less educated and Hispanic consumers are likely to benefit more from these types of resources, educators and professionals may want to focus on developing additional resources for low-literacy audiences and translating more materials into other languages such as Spanish. They may also want to take into consideration how technology and delivery format can affect some groups' access to this information such as older consumers who may not be as savvy when it comes to using the Internet. (See the U.S. Government Accountability report (2004) for additional insight into how financial literacy in general might be improved for these target populations.)

In addition to the previous findings, we also learned from this study that some of the characteristics that affect credit knowledge changed across the distribution. Most notably, the quantile regressions uncovered effects for education in the lower part of the conditional distribution of credit knowledge scores that differed significantly from the average effects found using the OLS method. Specifically, we found that education had a more positive effect on scores for those in the lower tail of the distribution. The implication is that formal financial education may be of greater benefit to individuals in the lower end of the credit knowledge 
distribution, while the impact may be somewhat less for individuals in the upper end of the distribution. However, while more advanced knowledge of credit reporting may be of greater benefit to those with lower levels of education, acquiring this knowledge may involve additional efforts by individuals to seek out such information, especially if consumer educators and financial professionals are not already targeting them.

With respect to financial experience, the most dramatic increases across the distribution were observed for having a mortgage or auto loan, having requested a credit report, having pulled one's credit score, and having disputed the contents of their credit report. We also found that those with higher scores were slightly more likely to have lived in one of the seven states where consumers could order a free copy of their credit report. Thus, giving consumers opportunities to gain hands-on, real world experience with credit is likely to also be of benefit. A first step might be for consumer educators and financial professionals to review existing curricula and programs related to credit reporting and strategically create, or enhance, existing opportunities for consumers to put their knowledge into practice. Given the key role that schooling appears to play, educators may also want to identify "teachable moments" for young consumers. For example, existing efforts within the public school system could be expanded to provide financial education and experiential learning opportunities related to credit reporting and other key financial concepts in high school curricula. According to the National Council on Economic Education (2005), 38 states now have personal finance standards built into their state education systems. Of these, 21 states require explicitly that the standards be implemented. In seven states, personal finance is a requirement for high school graduation (Idaho, Illinois, Kentucky, New York, Georgia, and Alabama). 
Many of the other covariates in our analysis exhibited quantile effects that did not differ significantly from the average effect. Even so, estimating a quantile model still proved to be a useful exercise. It confirmed that the influence of the other covariates was fairly uniform for individuals with varying levels of credit knowledge - a finding we could not have gleaned from an OLS analysis alone. Thus, the quantile analysis proved to be a useful tool for identifying specific subgroups of consumers that would likely benefit from more targeted financial education.

Overall, the findings from this study have important implications for consumer educators, financial professionals, and policymakers, especially with respect to national financial education strategies designed to improve consumers' financial well-being (U.S. GAO 2004). Although numerous programs and initiatives are under way to increase financial education, our findings identify specific subgroups of the population that may lack sufficient credit reporting knowledge and highlights specific areas where targeted financial education could increase consumers' knowledge and experience about credit. As we move forward, leading financial education experts may want to take this information into consideration as they continue to create national strategies and media campaigns that raise awareness about the importance of being financially knowledgeable, especially about credit reporting issues. 


\section{APPENDIX}

\section{Questions Used to Calculate Consumers' Credit Knowledge Score (23 questions, 56 points)}

\section{Credit Reports}

1. If I say a company is a "credit reporting agency," also known as a "credit bureau" or "consumer reporting agency," how would you describe what they do? (2 points)

2. To the best of your knowledge, which of the following phrases best describes a "credit reporting agency"? (1 point)

3. Can you name any of the nationwide credit reporting agencies? (4 points)

4. In your own words, what is a credit report? (2 points)

5. If you want to see your own credit, when are you able to order a copy? (1 point)

6. Some states have laws that allow residents to receive one or more free credit reports a year. Is your state one of these? (1 point)

7. If you don't live in a state that allows residents to receive one free credit report a year, about how much will a credit reporting agency charge you for a copy of your credit report? (1 point)

8. When a credit report is prepared on someone, the information can come from different sources. Please tell me which of the following sources you believe it can come from by answering yes, not, or don't know. (4 points)

9. After you take out a loan, a lender may provide information to a credit reporting agency about the loan and your history of paying it back. How many credit reporting agencies are lenders required to report to? (1 point)

10. For each of the following items, please tell me if you think it is or is not on a credit report or if you don't know whether it is on a credit report? (7 points)

11. If you do not pay your credit card bill, can the credit card company report this on your credit report? (1 point)

12. For about how long does information, such as making a late payment or going bankrupt, remain on your credit report? (1 point)

13. Who is permitted to see your credit report without your consent? (4 points)

14. Do you think your credit history can affect the following things? (7 points)

\section{Dispute Resolution}

15. If you feel information on your credit report is wrong, can you dispute, or request that a correction be made? (1 point)

16. If your credit report has incorrect information that you want corrected, which of the following will the credit reporting agency do? (1 point)

17. By law, if you are unable to resolve a disputed item with a credit reporting agency, which of the following do you have the right to do? (1 point)

18. If you resolve an inaccuracy on your credit report with one credit reporting agency, will the same inaccuracy automatically be corrected by all credit reporting agencies? (1 point)

\section{Credit Scores}

19. In your own words, what is a credit score? (2 points)

20. Which of the following best describes a credit score? ( 1 point)

21. Do you think the following situations affect your credit score in a positive way, has no effect, affects your score in a negative way, or don't know. (8 points)

22. What do you think a possible credit score, based on someone's credit history, is? (1 point)

FACT Act

23. There is a new law that affects your rights regarding credit reports and scores. Which of the following changes will be made? ( 3 points)

SOURCE: US GAO (2005) 


\section{REFERENCES}

American Association of Retired People. 2003. Consumer Experience Survey: Insights on Consumer Credit Behavior, Fraud and Financial Planning. Washington, D.C.: Author.

Avery, R.B., P.S. Calem, and G.B. Canner. 2004. Credit Report Accuracy and Access to Credit. Federal Reserve Bulletin, Summer: 297-322.

Avery, R.B., P.S. Calem, G.B. Canner and R.W. Bostic. 2003. An Overview of Consumer Data and Credit Reporting. Federal Reserve Bulletin, February: 47-73.

Bassett, G. W., M.-Y. S. Tam, and K. Knight. 2002. Quantile Models and Estimators for Data Analysis. Metrika, 55 (1): 17-26.

Bedard, K. 2003. School Quality and the Distribution of Male Earnings in Canada. Economics of Education Review, 22 (4): 395-407.

Bell, E. and R. I. Lerman. 2005. Can Financial Literacy Enhance Asset Building? Opportunity and Ownership Project, The Urban Institute, 9 (6): 1-7.

Braunstein, S. and C. Welch. 2002. Financial Literacy: An Overview of Practice, Research, and Policy. Federal Reserve Bulletin, November: 445-457.

Buchinsky, M. 1994. Changes in U.S. Wage Structure 1963-1987: Application of Quantile Regression. Econometrica, 62 (2): 405-458.

Buchinsky, M. 1998. Recent Advances in Quantile Regression Models: A Practical Guideline for Empirical Research. Journal of Human Resources, 33 (1): 88-126. The Dynamic changes in the Female Wage Distribution in the USA: A Quantile Regression Approach. Journal of Applied Econometrics, 13: 1-30.

Consumer Federation of America. 2003. Consumers Lack Essential Knowledge, and Strongly Support New Protections, on Credit Reporting and Scores. http://www.consumerfed.org. 
Consumer Federation of American and Providian. 2004. Most Consumers Do Not Understand Credit Scores According to a New Comprehensive Survey. http://consumerfed.org.

Eide, E. and M. H. Showalter. 1998. The Effect of School Quality on Student Performance: A Quantile Regression Approach. Economics Letters, 58 (3): 345-350.

Fox, J., S. Bartholomae, and J. Lee. 2005. Building the Case for Financial Education. The Journal of Consumer Affairs, 39 (1): 195-214.

Hilgert, M. A., J. M. Hogarth, and S.G. Beverly. 2003. Household Financial Management: The Connection Between Knowledge and Behavior. Federal Reserve Bulletin, July: 309-322.

Hogarth, J. M. 2002. Financial Literacy and Family \& Consumer Sciences. Journal of Family \& Consumer Sciences, 94 (1): 14-28.

Hogarth, J. M., S. G. Beverly, and M. A. Hilgert. 2003. Patterns of Financial Behaviors: Implications for Community Educators and Policymakers. Paper presented at the 2003 Federal Reserve System Community Affairs Research Conference, Washington, DC. http://www.federalreserve.gov/communityaffairs/national/CA_Conf_SusCommDev/pdf/h ogarthjeanne.pdf

Koenker, R., and G. Basset. 1978. Regression Quantiles. Econometrica, 46 (1): 33-50.

Koenker, R. and K. F. Hallock. 2001. Quantile Regression. Journal of Economic Perspectives, 15 (4): $143-156$.

Levin, J. 2001. For Whom the Reductions Count: A Quantile Regression Analysis of Class Size and Peer Effects on Scholastic Achievement. Empirical Economics, 26 (1): 221-246.

Lyons, A. C. 2005. Financial Education and Program Evaluation: Challenges and Potentials for Financial Professionals. Journal of Personal Finance, 4 (4): 56-68. 
Lyons, A. C., L. Palmer, K. S. U. Jayaratne, and E. Scherpf. 2006. Are We Making the Grade? A National Overview of Financial Education and Program Evaluation. The Journal of Consumer Affairs, 40 (2), forthcoming.

National Council on Economic Education. 2005. Survey of the States: Economic and Personal Finance Education in Our Nation's Schools in 2004. Washington, D.C.: Author. http://www.ncee.net

U.S. Government Accountability Office. 2005. Credit Reporting Literacy: Consumers Understood the Basics but Could Benefit from Targeted Educational Efforts (GAO-05223). http://www.gao.gov/docdblite/summary.php?rptno=GAO-05-223\&accno=A19577. U.S. Government Accountability Office. 2004. Highlights of a GAO Forum: The Federal Government's Role in Improving Financial Literacy (GAO-05-93SP). http://www.gao.gov/docdblite/summary.php?rptno=GAO-05-93SP\&accno=A13412. 
TABLE 1

Survey Responses to Select Credit Knowledge Questions $(N=1,578$; year=2004)

General Credit Report Knowledge

Knew the correct definition of a credit reporting agency (CRA) 82.0

$\begin{array}{ll}\text { Knew they had the right to obtain their credit report at any time } & 70.9\end{array}$

Knew information could remain on credit report for 7 to 10 years 46.8

Knew lenders are not required to report to any of the CRAs

Knowledge of Credit History Impact

$\begin{array}{ll}\text { Knew credit history could affect ability to get a loan } & 94.9\end{array}$

Knew credit history could affect interest rates on loans $\quad 80.9$

Knew credit history could affect insurance coverage and/or premiums 36.0

$\begin{array}{ll}\text { Knew credit history could affect employment decisions } & 32.8\end{array}$

$\begin{array}{ll}\text { Knew credit history could affect ability to rent an apartment } & 72.3\end{array}$

Knew credit history could not affect ability to receive Social Security benefits $\quad 70.6$

Knew credit history could not affect ability to get a driver's license 86.1

Knowledge of Credit Report Contents

$\begin{array}{ll}\text { Knew Social Security number was on report } & 71.2\end{array}$

$\begin{array}{lr}\text { Knew credit history was on report } & 81.8\end{array}$

$\begin{array}{ll}\text { Knew bankruptcies were on report } & 86.8\end{array}$

Knew race was not on report $\quad 59.4$

Knew income was not on report $\quad 37.5$

$\begin{array}{lr}\text { Knew balances in checking account were not on report } & 57.9\end{array}$

Credit Score Knowledge

$\begin{array}{ll}\text { Knew the correct definition of a credit score } & 68.4\end{array}$

$\begin{array}{ll}\text { Could name a number within a possible credit score range } & 28.2\end{array}$

Knowledge of Factors that Affect Credit Scores

Knew making late credit card payments could affect scores negatively $\quad 87.0$

Knew skipping loan payments could affect scores negatively $\quad 86.9$

Knew having a credit history for a short time could affect scores negatively 48.9

Knew frequently applying for credit could affect scores negatively $\quad 59.9$

Knew using most of your available credit could affect scores negatively $\quad 51.5$

Knew requesting a copy of your own report had no effect on credit scores $\quad 50.0$

Knew low checking account balances had no effect on credit scores $\quad 43.4$

Knowledge of Dispute Process

Knew they had the right to dispute information on their credit report $\quad 89.8$

$\begin{array}{ll}\text { Knew they could add a statement to their credit report } & 40.6\end{array}$

$\begin{array}{lr}\text { Knew CRAs investigate incorrect information for free } & 28.1\end{array}$ 
TABLE 2

Demographic Profile of the Sample by Quartiles According to Credit Knowledge Score (year=2004)

\begin{tabular}{|c|c|c|c|c|c|}
\hline \multirow[b]{2}{*}{ Variables } & \multirow[b]{2}{*}{$\begin{array}{c}\text { All }^{\mathrm{a}} \\
\mathrm{N}=1,578\end{array}$} & \multicolumn{4}{|c|}{ Credit Knowledge Score } \\
\hline & & $\begin{array}{c}\text { Quartile I } \\
(0-45)^{\mathrm{b}} \\
\mathrm{n}=418\end{array}$ & $\begin{array}{c}\text { Quartile II } \\
(46-55) \\
n=404\end{array}$ & $\begin{array}{c}\text { Quartile III } \\
(56-66) \\
n=416\end{array}$ & $\begin{array}{c}\text { Quartile IV } \\
(67-91) \\
n=340 \\
\end{array}$ \\
\hline Average Credit Knowledge Score ( $\%$ correct) & 55.0 & & & & \\
\hline \multicolumn{6}{|l|}{ Education Level (\%) } \\
\hline Less than high school & 10.4 & 32.8 & 7.1 & 3.9 & 1.4 \\
\hline High school & 30.4 & 39.2 & 39.5 & 28.2 & 14.7 \\
\hline Some postsecondary & 28.4 & 16.8 & 28.9 & 33.2 & 32.7 \\
\hline College degree or more & 30.7 & 10.8 & 24.5 & 34.6 & 51.1 \\
\hline \multicolumn{6}{|l|}{ Annual Household Income $(\%)^{\mathrm{c}}$} \\
\hline Below $\$ 25,000$ & 28.2 & 58.7 & 30.7 & 19.1 & 11.1 \\
\hline$\$ 25,000-\$ 49,999$ & 27.4 & 21.1 & 33.5 & 29.3 & 23.2 \\
\hline$\$ 50,000-\$ 74,999$ & 20.3 & 12.3 & 15.3 & 27.8 & 23.4 \\
\hline$\$ 75,000$ and above & 24.1 & 7.8 & 20.6 & 23.8 & 42.2 \\
\hline Age (years) ${ }^{d}$ & 45.2 & 48.2 & 46.0 & 43.6 & 43.9 \\
\hline \multicolumn{6}{|l|}{ Employment Status (\%) } \\
\hline Employed full-time or part-time & 60.4 & 41.2 & 53.7 & 69.1 & 74.8 \\
\hline Student & 3.7 & 3.3 & 4.9 & 3.8 & 2.5 \\
\hline Unemployed & 31.1 & 48.0 & 37.3 & 23.4 & 17.9 \\
\hline Other & 4.8 & 7.2 & 4.0 & 3.7 & 4.8 \\
\hline \multicolumn{6}{|l|}{ Ethnicity (\%) } \\
\hline White & 68.8 & 51.7 & 65.3 & 79.9 & 74.8 \\
\hline Black & 12.4 & 12.0 & 15.8 & 9.1 & 13.0 \\
\hline Hispanic & 13.9 & 32.0 & 13.0 & 7.0 & 6.4 \\
\hline Other & 4.9 & 4.3 & 5.9 & 3.9 & 5.7 \\
\hline \multicolumn{6}{|l|}{ Gender (\%) } \\
\hline Female & 51.6 & 60.5 & 49.4 & 49.8 & 48.2 \\
\hline Male & 48.4 & 39.5 & 50.6 & 50.2 & 51.8 \\
\hline \multicolumn{6}{|l|}{ Financial Experience (\%) } \\
\hline Lived in free credit report state & 12.8 & 9.3 & 9.9 & 14.2 & 17.7 \\
\hline Had a mortgage or auto loan & 77.0 & 53.0 & 76.8 & 82.8 & 92.3 \\
\hline Requested credit report & 57.8 & 24.7 & 46.6 & 67.8 & 88.6 \\
\hline Pulled credit score & 32.8 & 8.1 & 19.2 & 40.0 & 62.3 \\
\hline Disputed contents of report & 17.9 & 5.3 & 9.0 & 18.1 & 39.6 \\
\hline Experienced identity theft & 9.8 & 6.1 & 9.1 & 11.0 & 12.6 \\
\hline
\end{tabular}

SOURCE: US GAO (2005)

${ }^{a}$ The first column presents the descriptive statistics for the total sample, and the remaining columns present the findings for individuals according to four quartiles, where higher quartiles imply higher credit knowledge scores.

${ }^{\mathrm{b}}$ The range of scores for each quartile are presented in parentheses.

${ }^{\mathrm{c}}$ Note also that there were 145 missing observations for income $(\mathrm{N}=1,433)$.

${ }^{d}$ Note that there were 94 missing observations for age $(\mathrm{N}=1,484)$. 
TABLE 3

OLS and Quantile Regressions by Consumers' Credit Knowledge Score $(N=1,380$, year $=2004)$

\begin{tabular}{|c|c|c|c|c|c|c|c|}
\hline \multirow[b]{2}{*}{ Independent Variable } & \multicolumn{2}{|c|}{ OLS } & \multicolumn{5}{|c|}{ Quantiles by Credit Knowledge Score } \\
\hline & Coeff & SE & 0.10 & 0.25 & 0.50 & 0.75 & 0.90 \\
\hline \multicolumn{8}{|l|}{ Education Level (\%) } \\
\hline High school & 8.511 & $(1.153)^{* * *}$ & $15.038^{* * *}$ & $8.304 * * *$ & $7.007 * * *$ & $6.320 * * *$ & $7.301 * * *$ \\
\hline Some postsecondary & 11.493 & $(1.217)^{* * *}$ & $22.462 * * *$ & $11.786^{* * *}$ & $9.912 * * *$ & $8.887 * * *$ & $8.987 * * *$ \\
\hline College degree or more & 13.786 & $(1.273)^{* * *}$ & $24.624 * * *$ & $13.929 * * *$ & $11.939 * * *$ & $10.561 * * *$ & $13.363 * * *$ \\
\hline \multicolumn{8}{|l|}{ Annual Household Income (\%) } \\
\hline$\$ 25,000-\$ 49,999$ & 3.106 & $(0.843)^{* * *}$ & $4.605 * *$ & $3.571 * * *$ & $2.885 * * *$ & $3.111 * * *$ & $2.915 * * *$ \\
\hline$\$ 50,000-\$ 74,999$ & 2.937 & $(0.965) * * *$ & $4.699 *$ & 1.696 & $2.868 * *$ & $2.716^{* * *}$ & $3.121 * * *$ \\
\hline$\$ 75,000$ and above & 3.278 & $(1.003)^{* * *}$ & 2.632 & 1.429 & $3.523 * * *$ & $5.166 * * *$ & $3.556^{* * *}$ \\
\hline Age (years) & -0.093 & $(0.022)^{* * *}$ & -0.094 & $-0.089 * *$ & $-0.111 * * *$ & $-0.107 * * *$ & $-0.074 * * *$ \\
\hline \multicolumn{8}{|l|}{ Employment Status (\%) } \\
\hline Student & -3.333 & $(1.572)^{* *}$ & -5.357 & -2.054 & -2.747 & $-5.004 * * *$ & $-7.904 * * *$ \\
\hline Unemployed & -1.564 & $(0.791)^{* *}$ & -1.692 & -1.161 & -0.918 & $-1.669 *$ & $-2.398 * * *$ \\
\hline Other & -3.127 & $(1.569)^{* *}$ & -2.538 & $-4.643 * *$ & -1.791 & -2.637 & $-3.132 *$ \\
\hline \multicolumn{8}{|l|}{ Ethnicity (\%) } \\
\hline Black & 0.151 & $(0.940)$ & -0.188 & -0.714 & -0.539 & 0.735 & 0.930 \\
\hline Hispanic & -6.306 & $(0.987)^{* * *}$ & $-7.519 * * *$ & $-5.893 * * *$ & $-6.514 * * *$ & $-5.176^{* * *}$ & $-2.658 * * *$ \\
\hline Other & 1.311 & $(1.484)$ & 2.068 & -1.339 & 2.098 & 2.214 & 1.808 \\
\hline \multicolumn{8}{|l|}{ Gender (\%) } \\
\hline Male & 0.586 & $(0.605)$ & 1.786 & $1.786^{*}$ & 0.071 & -0.451 & $-1.453 * *$ \\
\hline \multicolumn{8}{|l|}{ Financial Experience (\%) } \\
\hline Lived in free credit report state & 1.377 & $(0.879)$ & 1.974 & $2.321 * *$ & 0.760 & $1.632 * *$ & $1.722 * *$ \\
\hline Had mortgage or auto loan & 3.728 & $(0.871)^{* * *}$ & 2.632 & $3.750 * * *$ & $2.815 * * *$ & $3.390 * * *$ & $2.492 * * *$ \\
\hline Requested credit report & 5.149 & $(0.736)^{* * *}$ & $4.699^{* *}$ & $5.714 * * *$ & $4.714 * * *$ & $3.292 * * *$ & $6.211 * * *$ \\
\hline Pulled credit score & 4.243 & $(0.732)^{* * *}$ & $5.827 * *$ & $4.821 * * *$ & $3.707 * * *$ & $4.120 * * *$ & $2.441 * * *$ \\
\hline Disputed contents of report & 5.127 & $(0.821)^{* * *}$ & $4.135^{*}$ & $6.607 * * *$ & $6.712 * * *$ & $5.134 * * *$ & $4.033 * * *$ \\
\hline Experienced identity theft & 1.144 & $(0.987)$ & 3.195 & 1.696 & -0.317 & -1.042 & -0.567 \\
\hline Intercept & 40.469 & $(1.572)^{* * *}$ & $17.387 * * *$ & $33.125 * * *$ & $44.518 * * *$ & $52.088 * * *$ & $55.836 * * *$ \\
\hline Pseudo $\mathrm{R}^{2}$ & 0.456 & & 0.316 & 0.267 & 0.261 & 0.248 & 0.221 \\
\hline
\end{tabular}

Note: $* * * \mathrm{p}<0.01, * * \mathrm{p}<0.05$, and $* \mathrm{p}<0.10$. Source for data is the US GAO (2005). Base categories include: white, income below $\$ 25,000$, employed full-time or part-time, female, less than high school. Robust standard errors are reported for the OLS regression. Observations in the analysis are equal to 1,380 due to missing observations for age and income categories. 
FIGURE 1

Kernel Density Estimates for Consumers' Credit Knowledge Score

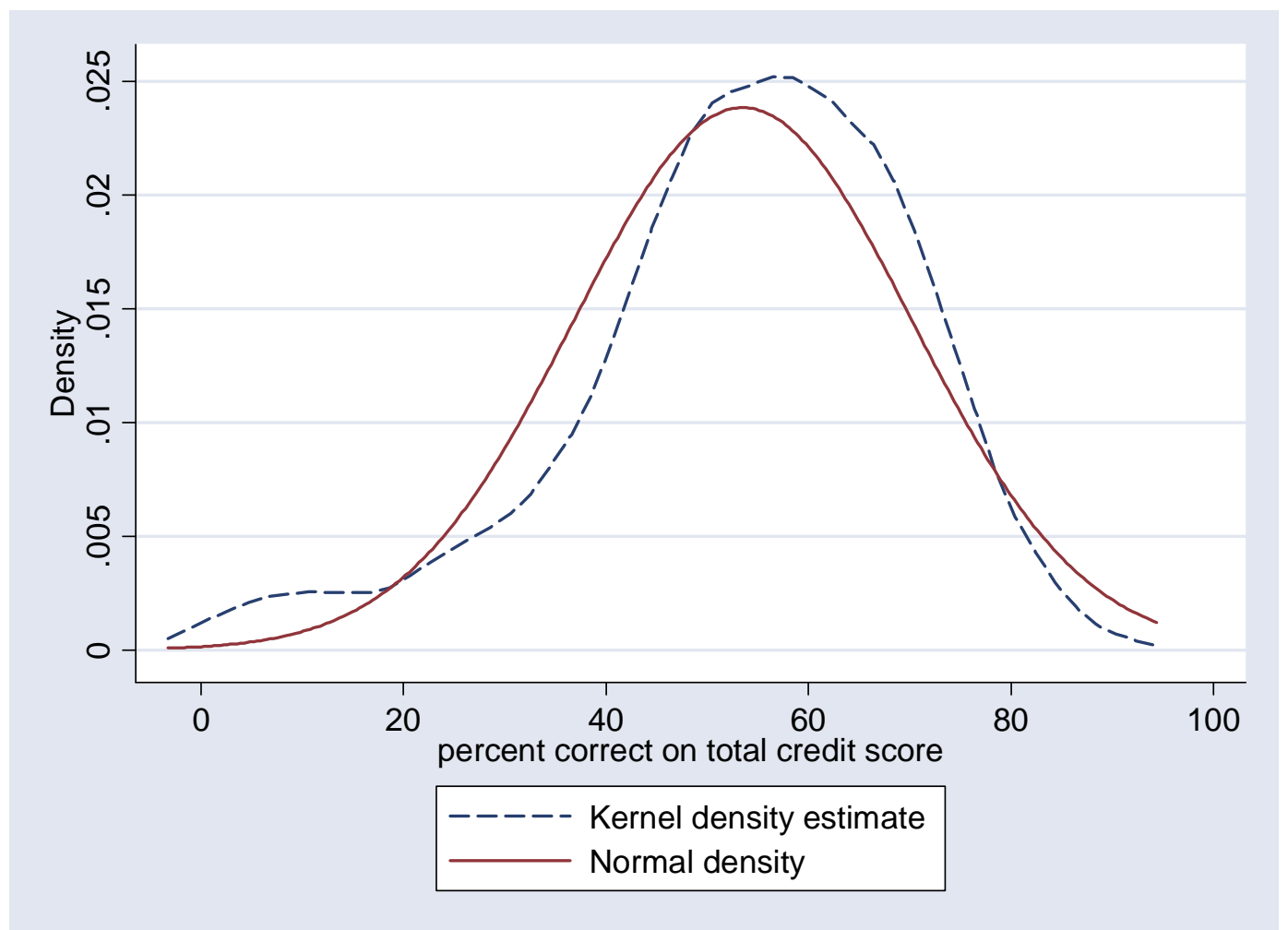


FIGURE 2

Ordinary Least Squares and Quantile Regression Estimates for Consumers' Credit Knowledge Scores ( $90 \%$ confidence intervals)
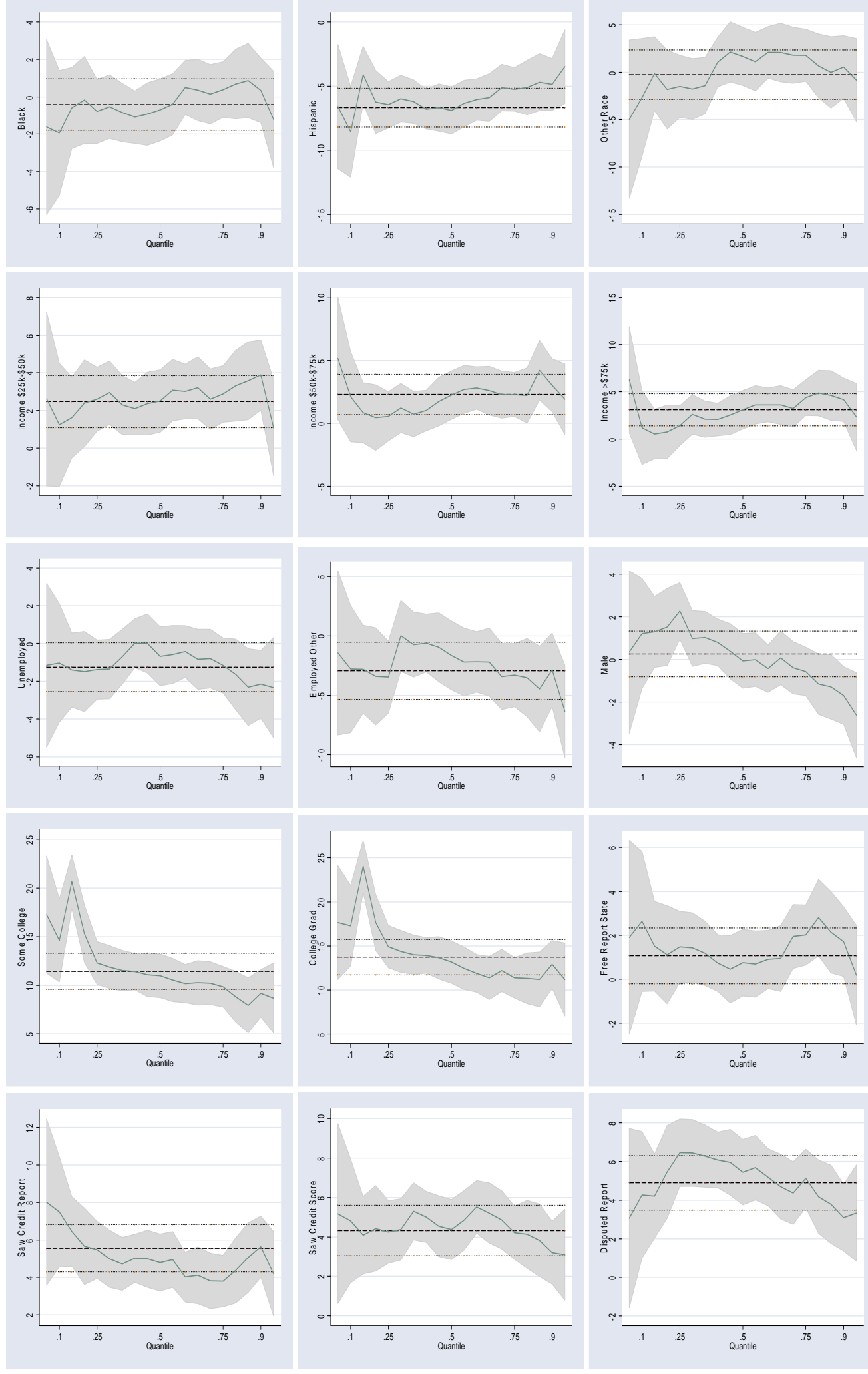
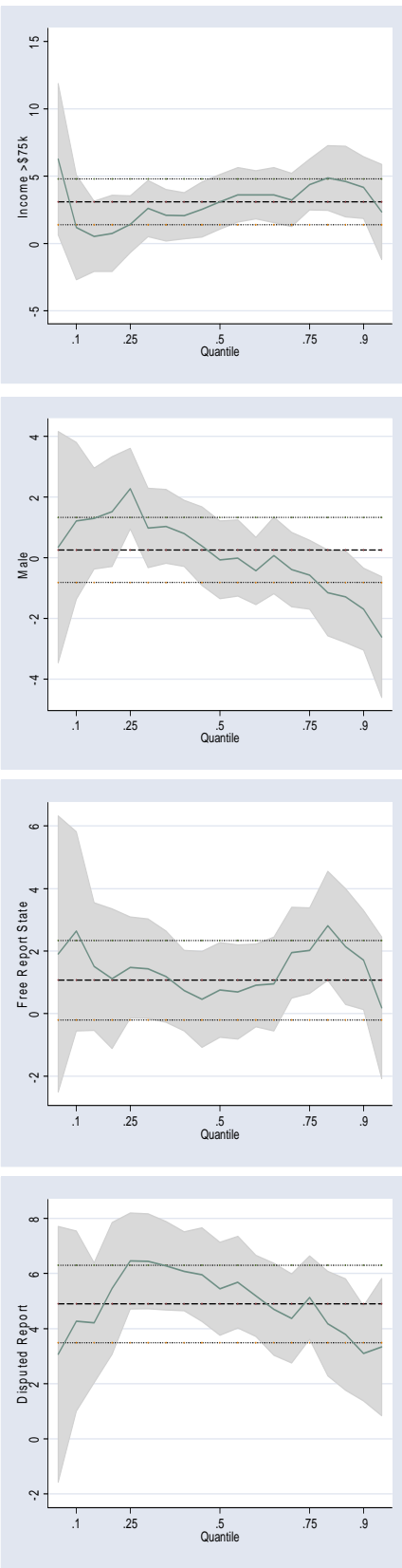
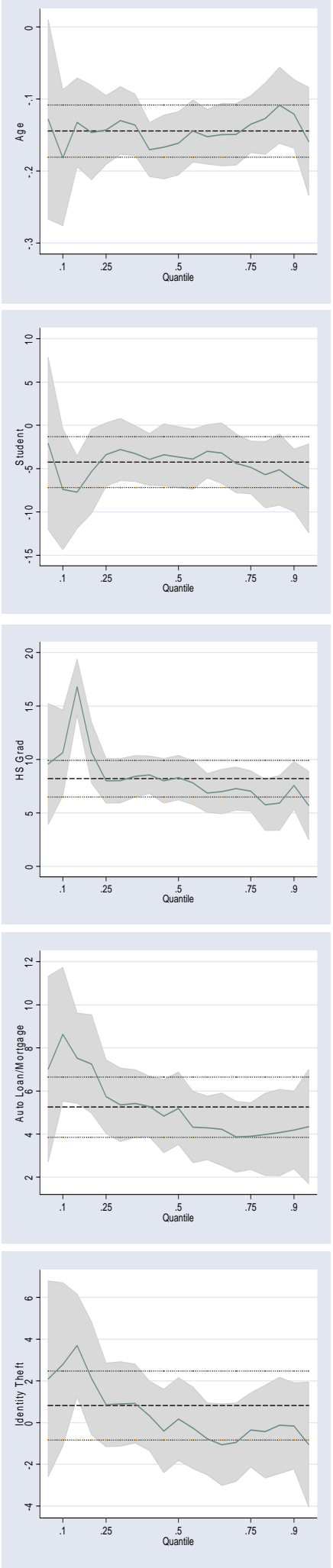